\title{
Castration, sexual experience, and female urine odor preferences in adult $\mathrm{BDF}_{1}$ male mice
}

\author{
ELIZABETH ROSE and LEE C. DRICKAMER \\ Williams College, Williamstown, Massachusetts 01267
}

\begin{abstract}
Olfactory preferences between urine odors from estrous and nonestrous female mice were tested using four groups of $\mathrm{BDF}_{1}$ male mice; sexually experienced or sexually naive and intact or castrated. The presence or absence of the testes was a significant factor affecting urine preference, but prior sexual experience was not a significant determinant of discrimination ability. Thus, olfactory preference, by males, for female urine from different stages of the estrous cycle is affected by castration but does not require previous sexual experience.
\end{abstract}

Studies using adult male rats have produced conflicting evidence on the importance of gonadal hormones and previous sexual experience on the ability to discriminate receptive (estrous) from nonreceptive (nonestrous) female urine. Carr, Loeb, and Wylie (1965) and Carr, Loeb, and Dissinger (1966) demonstrated that intact, sexually experienced male rats preferred receptive to nonreceptive female odor, while intact, sexually naive males and castrated males did not discriminate between the two types of female urine odor. These results are supported by the recent work of Lydell and Doty (1972) demonstrating that sexual experience was necessary for male rats to discriminate successfully estrous from diestrous female urine, and by the report of Stern (1970) that both the presence of testes and sexual experience in the form of mounting behavior were necessary for discrimination between odors of receptive and nonreceptive females. By contrast LeMagnen (1952) reported that intact, sexually naive rats preferred estrous to nonestrous odors, thus indicating that sexual experience may not be an important factor affecting the odor discrimination. In a futher study, Carr and Caul (1962) found that castrated male rats could be taught to discriminate between estrous and nonestrous female odors when they were given water reinforcement.

In mice, olfactory communication has received a great deal of study in recent years, including investigations of odors affecting sexual maturation (Vandenbergh, 1969; Drickamer, 1974), aggression (Ropartz, 1968), individual recognition (Bowers \& Alexander, 1967) and stress (Carr, Mortorano, and Krames, 1970). Several studies have reported on the discrimination of sexual odors on male social investigatory behavior (Davies and Bellamy, 1974). The purpose of the present investigation

This research was supported, in part, by United States Public Health Service Grant NH 24483 to Drickamer and Sloan Discretionary funds from Williams College. We thank Aubrey Manning, Christina Williams and John Gould for their technical assistance. We thank Dr. Thomas E. McGill for reading the manuscript and for sponsoring this paper, for which he takes full editorial responsibility.

Send reprint requests to: Lee C. Drickamer, Biology Department, Williams College, Williamstown, Massachusetts 01267. was to test the preferences of male $\mathrm{BDF}_{1}$ mice between estrous and nonestrous female urine using a cross-classified design with sexual experience and presence or absence of the testes as main treatment factors.

\section{METHOD}

\section{Subjects and Design}

Sixty BDF, (produced from C57BL/6 females $\mathrm{x}$ DBA/2 males; obtained from the Jackson Laboratory, Bar Harbor, Maine) male mice were randomly assigned at 6 weeks of age to one of four treatment groups in a 2 by 2 factorial design: (1) experienced and intact, (2) naive and intact, (3) experienced and castrated, or (4) naive and castrated. Each mouse was housed individually in an opaque plastic cage measuring $30 \times 15 \times 15 \mathrm{~cm}$ deep. A bedding of wood shavings and nesting cotton was changed weekly. All mice were provided with ad-lib food (Wayne Lab Blox) and water. Forty adult (80-day-old) female mice from a randomly bred closed-colony stock were used to collect urine and for providing sexual experience.

\section{Apparatus and Procedure}

Beginning at 6 weeks of age, each mouse to be given sexual experience was placed in an aquarium with an adult female 3-4 times per week for 30 -min test periods. Each of the 30 mice given experience was observed until the occurrence of one ejaculation (total average exposure to an estrous female $=$ $260 \mathrm{~min}$ ). At 12 weeks of age, one-half of this experienced group of mice and one-half of the naive mice were castrated.

Twenty of the female mice were ovariectomized and served to provide nonestrous test urine. The remaining 20 females were given an injection of 10 micrograms of estradial benzoate in $.02 \mathrm{cc}$ of peanut oil every other day to bring the mice into a condition of constant estrous as confirmed vy vaginal smears. These females were used to provide estrous test urine.

Beginning at 14 weeks of age, each of the 60 test males was given two $1 / 2-\mathrm{h}$ odor discrimination tests per week for 5 weeks. A clean 10-gallon aquarium was used as a test chamber. Two cotton balls, one with 10 drops of fresh estrous urine and one with 10 drops of fresh nonestrous urine were placed at opposite ends of the chamber. Fresh urine was collected each day from the urethras of the females using micropipettes. The positions of the cotton balls were varied for each successive test according to a sequence of random numbers. The amount of time the mouse was in contact with either of the cotton balls was recorded on two timers. 
The dependent variable used in analysing these data was the ratio of seconds spent investigating the estrous urine divided by the seconds investigating the nonestrous urine. Thus a ratio greater than 1.0 would indicate that the mouse spent more time investigating the estrous urine. The data were analyzed using a 3-way analysis-of-variance with one measure repeated, with $\alpha=$ .05 and $\mathrm{N}=15 /$ cell. The two main treatment factors were sexual experience and presence or absence of the testes, and the repeated measure was the 10 tests given each mouse.

\section{RESULTS}

All test groups investigated the estrous urine more than the nonestrous urine (Table 1). The analysis of variance revealed (1) there was a significant gonadal condition effect on urine preference $[\mathrm{F}(1,560)=10.46$; $\mathrm{p}<.01$ ] , (2) experience was not a significant variable affecting urine preference $[\mathrm{F}(1,560)=.19, \mathrm{p}<.50]$, (3) there were no differences in responses across test days and (4) there were no significant interaction effects. Intact males $(\overline{\mathrm{X}}=1.63)$ investigated the estrous urine significantly more than castrated males $(\overline{\mathrm{X}}=1.30)$, while there was no difference between the investigation scores for sexually experienced males $(\overline{\mathrm{X}}=1.44)$ and naive males $(\overline{\mathrm{X}}=1.48)$. For each of the four experimental test groups a parametric $t$ test indicated the mean ratio was significantly $(\mathrm{p}<.05)$ larger than 1.0. For all test mice, the average time spent investigating either odor source was $130 \mathrm{sec}$ out of a possible $1800 \mathrm{sec}$; mice spent a great deal of time exploring other aspects of the aquarium, moving around and/or grooming.

Sexually naive males were more variable in their responses to the two types of female urine as evidenced by the larger standard errors with these means (Table 1).

\section{DISCUSSION}

There is an important distinction between the ability of mice to discriminate between odors and their odor preferences. Presence or absence of the testes and previous sexual experience could affect either of these two response measures; the mice might be capable of discriminating between two odors, yet show no preference. The results of the present investigation demonstrate that testicular condition, but not previous sexual experience, is a significant factor affecting the preferences of adult male $\mathrm{BDF}_{1}$ mice between estrous and nonestrous female urine. All groups showed some preference for the estrous female urine, implying that discrimination between odors from urine of estrous or nonestrous females may not be affected by either gonadal condition or previous sexual experience. However, intact males, with or without previous sexual experience, showed a significantly higher preference than castrated males. Testicular hormones may not be necessary for making the odor discrimination, but the data show that intact males either (1) have a stronger preference for estrous urine than castrates, or (2) can discriminate more exactly than castrates between the estrous and nonestrous urine. The latter explanation would mean that the presence or absence of testicular hormones affects either central or peripheral sensory filter mechanisms.

The results of this study are in accord with the earlier findings on rats (LeMagnen, 1952), and more recent work by Carr et al, (1966) showing that castrates showed no preference between estrous and nonestrous urine. However, Carr and colleagues (1965, 1966), Lydell and Doty (1972) and Stern (1970) all
Table 1

Mean Investigation Ratio ( \pm SE) of Estrous to Nonestrous Urine for BDF ${ }_{1}$ Male Mice Under Two Conditions of Sexual Experience and Presence or Absence of Testes

\begin{tabular}{lccccc}
\hline & \multicolumn{2}{c}{$\begin{array}{c}\text { Sexually } \\
\text { Experienced }\end{array}$} & \multicolumn{2}{c}{$\begin{array}{c}\text { Sexually } \\
\text { Naive }\end{array}$} & Mean \\
\hline Intact & $1.68(.08)$ & 1.58 & $(.14)$ & 1.63 \\
Castrated & $1.20 \quad(.07)$ & 1.39 & $(.11)$ & 1.30 \\
Mean & 1.44 & 1.48 & & \\
\hline
\end{tabular}

Note-N $=15$ per cell.

found that intact, sexually naive rats did not demonstrate preferences between urine from females of different stages of the estrous cycle. In contrast we found that naive intact male house mice preferred the estrous to nonestrous urine, indicating an ability to discriminate different odors. This difference in results between rats and mice could be a function of many factors including species, season of testing, age at the time of surgery or testing, or experimental techniques of measuring odor preferences. An important follow-up experiment to the one we have conducted would test differences in urine preferences between various strains of house mice. Some of the pheromonal phenomena which have been elucidated in mice are generalizable across different strains (Cowley \& Wise, 1971; Drickamer, 1974; Kennedy \& Brown, 1970; Vandenbergh, 1969 ); while other pheromonal mechanisms, like the Bruce-effect, appear to be more strain specific (Bronson, 1970; Whitten, 1966).

Three important points emerge from the present investigation; (1) while all test groups of male mice exhibited some preference for estrous female urine over nonestrous urine, intact males showed a significantly stronger preference and previous sexual experience was not a significant variable affecting urine odor preference; (2) there is an important distinction between the ability to discriminate odors and odor preferences; and (3) differences between rats and mice with respect to the effects of castration and previous sexual experience on the ability to discriminate female odors suggest that strain differences among house mice should be investigated.

\section{REFERENCES}

Bowers, J. M., \& Alexander, B. K. Mice: Individual recognition by olfactorv cues. Science. 1967. 158. 1208-1210.

Bronson, F. Rodent pheromones. Biology of Reproduction, $1970,4,344-357$.

Carr, W. J. \& Caul, W. F. The effect of castration in the rat upon the discrimination of sex odors. Animal Behaviour, 1962, 10, 20-27.

Carr, W. J. Loeb, L. S., \& Dissinger, M. L. Responses of rats to sex odors. Journal of Comparative and Physiology Psychology., 1965, 59, 370-377.

Carr, W. J., Loeb, L. S., \& Wylie, N. R. Responses to feminine odors in normal and castrated male rats. Journal of Comparative and Physiological Psychology, 1966, 62, 336-338.

Carr. W. J.. Mortorano, R, D., \& Krames, L. Responses of mice to odors associated with stress. Journal of Comparative and Physiological Psychology, 1970, 71, 223-228.

Cowley, J. J., $\&$ wise, D. R. Some effects of mouse urine on neonatal growth and reproduction. Animal Behavior, 1972, 20, 499-506.

Drickamer, L. C. Sexual maturation of female house mice: Social inhibition. Developmental Psychobiology, 1974, 7, 257-265.

Kennedy, J. M., \& Brown, K. Effects of male odor during infancy on the maturation, behavior and reproducton of female mice. Developmental Psychobiology, 1970, 3, 179-189.

LeMagnen, J. Les phenomenes olfacto-sexuels chez le rat blanc. Archieves des Sciences Physiologiques, 1952, 6, 295-332.

Lydell, K. \& Doty, R. L. Male rat odor preferences for female Urine as a function of sexual experience, urine age and urine source. Hormones and Behavior, 1972, 3, 205-212. 
Ropartz, P. Demonstration of an increase of locomotor activity of groups of female mice to the od or of a group of strange males. C. R. Hebd. Seances Ser. D Sci. Natur., 1968, 267, $9.341-2.343$.

Scott, J. W., \& Pafaff, D. W. Behavioral and electrophysiological responses of female mice to male urine odors. Physiology and Behavior, 1970, 5, 407-411.

Stern, J. J. Responses of male rats to sex odors. Physiology \&
Behavior, 1970, 5, 519-524.

Vandenbergh, J. G. Male odor accelerates female sexual maturation in mice. Endocrinology, 1969, 84, 658-660.

Whitten, W. K. Pheromones and mammalian reproduction. In. E. McLaren (Ed.), Advances in reproductive physiology. Vol. I, New York, Academic, 1966.

\title{
Eyewitness testimony: The influence of the wording of a question
}

\author{
ELIZABETH F. LOFTUS \\ University of Washington, Seattle, Washington 98195 \\ and \\ GUIDO ZANNI \\ New School for Social Research, New York, New York 10011
}

\begin{abstract}
Two experiments are reported in which subjects viewed a film of an automobile accident and then answered questions about events occurring in the film. Relative to questions containing an indefinite article (e.g., Did you see $a$ broken headlight?), questions which contained a definite article (e.g., Did you see the broken headlight?) produced (1) fewer uncertain or "I don't know" responses, and (2) more "recognition" of events that never, in fact, occurred. The results, which are consistent with the view that questions asked subsequent to an event can cause a reconstruction in one's memory of that event, have important implications for courtroom practices and eyewitness investigations.
\end{abstract}

An automobile accident is a highly complex and sudden event often lasting only a few seconds. Is our perception, recollection, and verbalization of such an incident an identical copy of the original event? Most researchers in the field of human memory would agree that the answer to this question is "no." There are numerous ways to influence (and often distort drastically) the recollections of a witness. One relatively easy way is to vary the method by which the recollection is elicited or to vary the form in which questions are asked about the recollection.

Much of the research in this area has indicated that when people are forced to answer specific questions, rather than to report freely, their reports are more complete but less accurate (Cady, 1924; Gardner, 1933; Marquis, Marshall \& Oskamp, 1972; Marston, 1924; Whipple, 1909). Furthermore, the accuracy of an answer to a specific question can be noticeably influenced by the wording of the question itself. By changing one or two words in a question, clear-cut variations have been shown to appear in as diverse areas as a subject's report of hypnotic experiences (Barber, 1969) and in his estimates of the speed of a moving vehicle (Loftus \&

This research was supported by the Urban Mass Transportation Administration, Department of Transportation, Grant No. WA-11-0004. Requests for reprints should be sent to Elizabeth F. Loftus, Psychology Department, University of Washington, Seattle, Washington 98195.
Palmer, in press). The wording of a question is such an important matter, that a recent book intended to help potential questionnaire designers (Oppenheim, 1966) devotes an entire chapter to the topic of question wording.

The present research demonstrates the influence of very small changes in the wording of a question in a situation in which subjects viewed a film of an automobile accident and then answered questions about events that did and did not occur in the film. For some of the questions, the English article the (the definite article) was used, as in "Did you see the broken headlight?" For other questions the article $a$ (the nondefinite or indefinite article) was used resulting in questions like "Did you see a broken headlight?" Previous research on the definite and indefinite article has been equivocal as to whether there is a difference in influence between the two. Muscio (1915) concluded that the more reliable form of question was one that did not use the definite article, whereas Burtt (1931) reported that $a$ and the are about equally suggestive.

What is the difference between the and $a$, and why should use of these articles produce differential behavior on the part of eyewitnesses? On this topic, a number of psychologists have recently had something to say (e.g., Anderson \& Bower, 1973; Brown, 1973; Chafe, 1972; Maratsos, 1971; Osgood, 1971); most have made the 